\title{
Effect of Freund's adjuvant on the mitogenic responses of rat lymphocytes
}

\author{
L. KOUROUNAKIS AND M. A. KAPUSTA \\ From the Lady Davis Institute for Medical Research of the Jewish General Hospital, \\ the Department of Medicine, Subdivision of Rheumatology, Jewish General Hospital, \\ Montreal, Quebec, Canada
}

The administration of Freund's adjuvant to rats induces a disease characterized by inflammatory lesions of synovial membrane, eye, skin, and genitourinary system (Pearson and Wood, 1959). Adjuvantinduced disease (AID) has been compared to rheumatoid arthritis and Reiter's syndrome in man (Pearson, Waksman, and Sharp, 1961). AID is generally considered to be a disease of thymicdependent cell-mediated immunity, mainly because it can be transferred between highly inbred animals by means of intact lymphoid cells (Waksman and Wennersten, 1963).

The possible virus aetiology of AID has been discussed in previous studies (Kapusta and Mendelson, 1969). The mixed lymphocyte proliferative response in vitro was studied using spleen cells from normal and Freund's adjuvant-treated rats from the same inbred strain in order to determine whether there were significant virus-induced surface antigenic differences between these two populations of cells. The proliferative responses of lymphoid cells from adjuvant-treated rats was found to be unpredictable. In order to clarify this problem, it was decided to study the responsiveness of these cells to various mitogens.

The results to be presented demonstrate that Freund's adjuvant alters the responses of lymphocytes from various lymphoid organs to phytohaemagglutinin (PHA) and pokeweed mitogen (PWM) in widely different ways. Further, these results differ from those previously reported in mice (Scott, 1972 a,b).

The differences noted may, in part, explain why the rat is the only species which develops a rheumatic disease in response to adjuvant administration.

\section{Material and Methods}

RATS

Highly inbred male Fisher rats (Simonsen Lab., Gilroy, California) weighing between 180 and $220 \mathrm{~g}$., housed in groups of four or five in large cages with wire mesh floors, and receiving a diet of commercial food pellets and water ad lib., were used throughout this study.

\section{ADJUVANT INJECTION}

Desiccated Mycobacterium butyricum (Difco Lab., Detroit, Michigan) was suspended in light mineral oil (Fisher) to give a suspension of $6 \mathrm{mg}$. M. butyricum per $\mathrm{ml}$. Normal saline was added in a ratio of $1 / 50 \mathrm{v} / \mathrm{v}$ and the suspension was emulsified for $10 \mathrm{~min}$. in a Sorvall OmniMixer at maximum speed and then autoclaved. A 21-gauge needle was used to inject $0 \cdot 1 \mathrm{ml}$. of this adjuvant into the skin of the distal third of the tail.

\section{CELL SUSPENSION AND CULTURES}

Spleen, inguinal lymph node, and thymus cell suspensions were prepared by gently pressing those organs through a 50-mesh screen into cold medium 199 (Microbiological Associates, Bethesda, Maryland). Bone marrow cell suspensions were obtained by cutting the distal and proximal ends of each femur and tibia and flushing the marrow cavity with medium 199. The cells were then centrifuged at $100 \mathrm{~g}$. for $10 \mathrm{~min}$., the supernatant discarded, and the cells re-suspended in medium for counting. The final mixture contained $10^{6}$ lymphoid cells and 100 i.u. penicillin and $200 \mu \mathrm{g}$. streptomycin per ml. medium 199 enriched with 20 per cent. foetal calf serum (Microbiological Associates). Blood was aspirated from the abdominal aorta with a heparinized syringe and suspended in a ratio of $1 / 20 \mathrm{v} / \mathrm{v}$ in medium 199 according to the method of Pauly, Sokal, and Han (1972). Viability tests were done by the trypan blue dye exclusion method.

The mitotic response of the lymphocytes was studied according to the method of Singhal and Richter (1968). In brief, triplicate samples of $4 \mathrm{ml}$. each were placed in Falcon plastic $17 \times 100 \mathrm{~mm}$. tubes, tightly capped, and placed in an incubator at $37^{\circ} \mathrm{C}$. for $72 \mathrm{hrs}$. Two $\mu \mathrm{c}$. of tritiated thymidine ( 2 curies/mM) (New England Nuclear, Boston, Mass.) were added for the last $18 \mathrm{hr}$ of culture. The optimum time of the lymphocyte culture response of normal and adjuvant-treated rats was found to be $72 \mathrm{hrs}$.

The tubes were then centrifuged at $500 \mathrm{G}$. for $10 \mathrm{~min}$., the supernatants discarded, the precipitated cells washed twice with $2 \mathrm{ml}$. 5 per cent. cold trichloroacetic acid 
(TCA), (in the case of blood cells, 3 per cent. cold acetic acid was used), then dissolved in $0.5 \mathrm{ml}$. hydroxide of hyamine (10-X Packard, Downers Grove, Ill.) for $20 \mathrm{hrs}$. and transferred to counting vials, using two washes of $0.3 \mathrm{ml}$. absolute ethanol. $0.5 \mathrm{ml}$. distilled $\mathrm{H}_{2} \mathrm{O}$ and $10 \mathrm{ml}$. Aquaflor (New England Nuclear) were added to the counting vials, which were stored for $24 \mathrm{hrs}$ at $4^{\circ} \mathrm{C}$. before counting. The results are expressed as a ratio (stimulation index): $\mathrm{cpm}$ in stimulated cultures/cpm in unstimulated cultures of control or AID rats.

\section{MITOGENS}

The optimum mitogenic amount of bacto-phytohaemagglutinin (PHA) (Difco) in normal and adjuvant-treated rats, was found to be $0.01 \mathrm{ml}$. of the original solution per culture tube which was added just before incubation. Similarly $0.06 \mathrm{ml}$. reconstituted pokeweed mitogen (PWM) (Gibco, Grand Island, N.Y.) and $0.1 \mathrm{mg}$. in $0.1 \mathrm{ml}$ medium of lipopolysaccharide from $E$. coli $(0.55: \mathrm{B} 5$ LPS-c) (Difco) were used per culture tube.

Normal rats were surgically thymectomized or sham operated. A number of different groups of normal rats were injected intraperitoneally (IP) with schedules ranging from 25 to $80 \mathrm{mg}$. hydrocortisone acetate or succinate (Roussel (Canada) Ltd.), given either as a single injection or twice daily for 4 days.

\section{STATISTICAL ANALYSIS}

The significance of the results (differences between AID rats and normal rats) was evaluated by Student's t test.

\section{Results}

Fig. 1 shows the response to PHA of cells from various lymphoid organs of normal rats and of adjuvanttreated rats 7 and 14 days after treatment. There is a significant decrease in response to PHA of splenic lymphocytes from adjuvant-treated rats as compared to the normal. The responses to PHA of blood, thymus, and bone marrow cells from AID rats are similar to those of normal rats. There is an increased responsiveness in cells derived from inguinal lymph nodes 14 days post-adjuvant. Not shown on the graph are data which demonstrated a return of the response of spleen cells to normal by about Day 35 post-adjuvant.

The decreased response to PHA of splenic lymphocytes in AID may have been due to loss of T cells

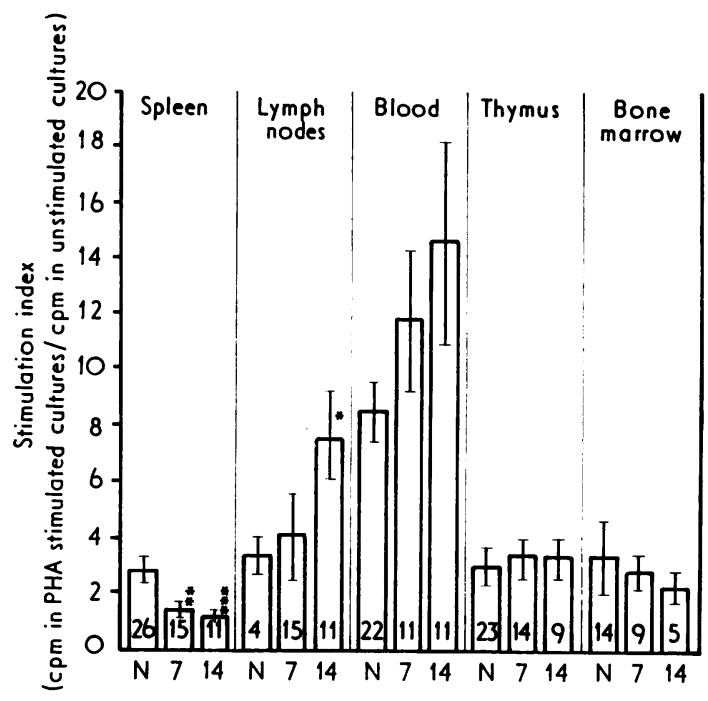

FIG. 1 Response in vitro of normal and adjuvanttreated rat lymphoid cells to phytohaemagglutinin $(P H A)$. The standard error and number of individual experiments per group are shown in the bars. Normal lymph node lymphocytes were pooled from twenty rats in each of four separate experiments. The significance of suppression or augmento tion of response of $A I D$ rats in comparison to normal rats is given as follows:

$$
*=P<0.05 \quad * *=P<0.01 \quad \stackrel{*}{*}=P<0.005
$$

from the spleen, to a change in the characteristics of response to PHA after adjuvant injection, or to the presence of an inhibitor in the cultures. The time response, various concentrations of PHA, and the addition of normal thymic extracts were studied in cultures from adjuvant-treated rats without any difference in response. Furthermore, neither supernatants from spleen cell cultures nor serum from adjuvant-treated rats added to cultures of normal spleen cells produced inhibition of response to PHA.

However, in three separate experiments when the spleen cells themselves from rats 14 days after adjuvant injection were added to normal spleen cells in equal numbers, there was significant inhibition of response to PHA of the normal spleen cultures. A representative experiment is shown in Table $\mathbf{I}$.

Table I Inhibition of PHA responsiveness of normal spleen cells by addition of Freund's adjuvant-treated spleen cells

\begin{tabular}{|c|c|c|c|}
\hline Stimulation & Normal cells & 14 days post-adjuvant-treated cells & Normal and adjuvant-treated cells \\
\hline c.p.m. unstimulated cells & $5,450 \pm 1,250$ & $4,991 \pm 791$ & $5,454 \pm 406$ \\
\hline c.p.m. PHA-stimulated cells & $25,322 \pm 3,300$ & $2,944 \pm 938$ & $7,511 \pm 682$ \\
\hline Stimulation index & $4 \cdot 64$ & 0.59 & $1 \cdot 37$ \\
\hline
\end{tabular}


The responses to pokeweed mitogen (PWM) are shown in Fig. 2. There is no difference in the response of splenic cells from normal and AID rats. In contrast, significant differences from normal are noted in lymph nodes, blood, thymus, and bone marrow. There was an increased responsiveness of lymph node lymphocytes and a decrease in the thymus, blood, and bone marrow.

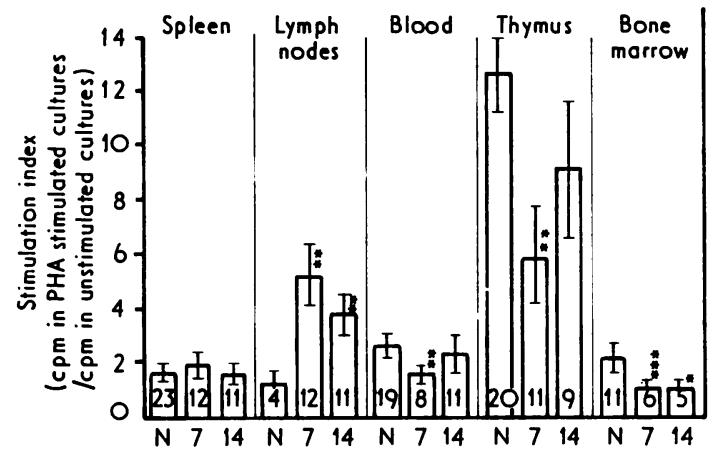

FIG. 2 Response in vitro of normal and adjuvant-treated rat lymphoid cells to pokeweed mitogen (PWM). The standard error and number of individual experiments per group are shown in the bars. Normal lymph node lymphocytes were pooled from twenty rats in each of four separate experiments.

The significance of slippression or augmentation of response of AID in comparison to normal rats is given as follows:

$$
*=P<0.05 \quad * *=P<0.01 \quad \stackrel{*}{*}=P<0.005
$$

The mitogenic response to bacterial lipopolysaccharide (LPS) was studied in the same way. No differences were noted from normal. LPS was generally poorly mitogenic for rat spleen, blood, thymus, and lymph node lymphocytes. Bone marrow cells failed to respond to LPS.

The AID rats showed atrophy of the thymus gland (Table II). Atrophy was present by Day 7 and persisted throughout the experiment.

Similar studies with PHA and PWM were done in normal, surgically thymectomized, and sham operated rats after 7, 14, and 28 days. Each group contained six rats. No differences were found from normal in all organs.

Similar studies with PHA and PWM were also done on 27 normal rats treated with intraperitoneal hydrocortisone acetate or succinate in doses sufficient to cause thymic atrophy (Table II). The animals were studied 2 and 4 days after the first administration of corticosteroid. No differences were noted from normal in all organs.

Similar studies with PHA and PWM were done in rats 7 and 14 days after injection of $M$. butyricum in saline or with mineral oil alone. No differences were noted from normal in all organs.
Table II Thymic weight in normal, adjuvanttreated, and corticosteroid-treated rats

\begin{tabular}{|c|c|c|c|c|}
\hline \multirow[t]{2}{*}{ Type of thymus } & \multirow{2}{*}{$\begin{array}{l}\text { Number } \\
\text { of rats }\end{array}$} & \multicolumn{2}{|c|}{ Weight $(g)$} & \multirow[t]{2}{*}{ P value } \\
\hline & & Mean & S.E. & \\
\hline $\begin{array}{l}\text { Normal* } \\
7 \text { days post-adjuvant }\end{array}$ & $\begin{array}{l}4 \\
4\end{array}$ & \multicolumn{2}{|c|}{$\begin{array}{l}0.2906 \pm 0.0145 \\
0 \cdot 1916 \pm 0.0089\end{array}$} & $<0.001$ \\
\hline $\begin{array}{l}\text { Normal* } \\
14 \text { days post-adjuvant }\end{array}$ & 4 & \multicolumn{2}{|c|}{$\begin{array}{l}0.2025 \pm 0.0032 \\
0.1275 \pm 0.0032\end{array}$} & $<0.001$ \\
\hline $\begin{array}{l}\text { Normal* } \\
\text { Corticosteroid } \dagger\end{array}$ & $\begin{array}{l}4 \\
8\end{array}$ & \multicolumn{2}{|c|}{$\begin{array}{l}0.2906 \pm 0.0112 \\
0.1881 \pm 0.0113\end{array}$} & $<0.001$ \\
\hline
\end{tabular}

* Different weights of normal controls due to use of different batches of rats at different times.

$\dagger$ Hydrocortisone acetate $\mathbf{1 0} \mathrm{mg}$. IP twice daily for 4 days.

\section{Discussion}

These experiments demonstrate that Freund's adjuvant has widely different effects on PHA as compared to PWM and LPS responsive populations of lymphocytes derived from rat spleen, lymph nodes, blood, thymus, and bone marrow. Spleen cells from 7 or 14 day post-adjuvant-treated rats have been demonstrated to be markedly unresponsive to stimulation with PHA while they are normally responsive to PWM or LPS.

It is generally accepted that, in mature mice, lymphocytes which respond to PHA stimulation are primarily $T$ cells (Greaves, Roitt, and Rose, 1968; Doenhoff, Davies, Leuchars, and Wallis, 1970) while those responding to PWM are different populations of cells, presumed at present to be a mixture of T and B cells (Stockman, Gallagher, Heim, South, and Trentin, 1971; Janossy and Greaves, 1972). Those responding to bacterial lipopolysaccharides (LPS) are B cells (Janossy, Shohat, Greaves, and Dourmashkin, 1972).

The PWM response in the normal rat thymus gland is quite large as compared to that of PHA, suggesting the presence of many B cells (Figs 1 and 2). However, the reactive populations to PWM and PHA have been defined in studies of peripheral lymphoid organs which contain mainly mature lymphocytes. About 95 per cent. of the lymphoid cells in the thymus gland are immature (Cohen and Claman, 1971) and may respond differently to these mitogens or, in fact, many of the immature thymic lymphocytes may be B cell-like.

The differences in the response profiles to each of these mitogens in the present experiments with rats are probably due to the fact that each mitogen stimulates a different cell population.

Many explanations have been proposed to account for decreased PHA responses in splenic lymphocytes from adjuvant-treated animals. Rodey and Good (1969) previously noted a decrease in PHA responsiveness of mouse splenic lymphocytes after the 
intraperitoneal administration of Freund's adjuvant. These authors postulated that the effect might be related to adjuvant-induced thymic atrophy. A similar temporary depression of spleen cells to PHA stimulation was observed by Folch and Waksman (1972) within a few days of adult thymectomy in rats. However, in the present experiments, neither surgical ablation of the thymus nor corticosteroidinduced thymic atrophy induced any changes in PHA or PWM responses of lymphocytes derived from rat spleen, lymph nodes, blood, thymus, and bone marrow.

During the course of this work, Scott (1972a, b) reported that in mice $C$. parvum adjuvant caused an inhibition of PHA response in blood and splenic lymphocytes, as well as inhibition of response to PWM of splenic lymphoid cells. He demonstrated that spleen cells but not supernates from $C$. parvum treated mice would inhibit the PHA responses of normal splenic lymphoid cells. Furthermore, removal of the macrophages from the spleens of $C$. parvum treated animals would restore the PHA responses to normal. This is of interest since Gery and Waksman (1972) have found that normal mouse macrophages produce a factor which stimulates the PHA responsive $T$ cells. Our data support the presence of some inhibitory effect of spleen cells from Freund's adjuvant-treated rats on the PHA responses of normal splenic lymphoid cells.

The PHA and PWM profiles show a decrease in PHA responsiveness in splenic lymphocytes and a decrease in PWM responsiveness in the blood, bone marrow, and thymic lymphocytes. There is a coincidental increase of PHA and PWM responses in lymphocytes from inguinal lymph nodes which do not drain the primary injection site of adjuvant. This suggests that Freund's adjuvant may bring about a redistribution of both $T$ and possibly $B$ lymphocytes with their accumulation in peripheral lymph nodes. This does not rule out the possibility that local maturation and proliferative changes may play some role.

The present experiments with Freund's adjuvant fail to show the inhibition of response of blood lymphocytes to PHA and splenic lymphocytes to PWM shown by Scott (1972a).

The differences between these experiments and those in mice may be due to the type of adjuvant used, to its mode of administration, or to species differences. Since the rat is the only species which develops a rheumatic disease in response to Freund's adjuvant, further definition of these differences in relation to the function of adjuvants in general and of AID in particular will be required to determine whether these differences are at all related to the cause of AID, to the results of this disease, or to a combination of both.

\section{Summary}

The mitogenic responses to PHA, PWM, and bacterial LPS were studied in lymphocytes from spleen, lymph nodes, blood, thymus, and bone marrow both in normal rats and in rats with adjuvant-induced disease. The changes in PHA and PWM responses largely differed from each other in the various organs studied. There was a decreased response of adjuvanto treated spleen cells to PHA and of blood, thymus and bone marrow to PWM. There was an increasee responsiveness of lymph node cells to PHA and PWM. Responses to bacterial LPS remained essentially normal. These data differ from those in adjuvanttreated mice. Whether these differences are related to the cause of adjuvant-induced disease, to the effect of the disease, or to a combination of these factors remains to be determined.

The authors wish to thank Mr. A. Zilbergold and Mr. M. Lazarus, Medical Students, for their excellent technical assistance, and Dr. M. Richter for reviewing the manuscript.

\section{References}

Cohen, J. J., And Claman, H. N. (1971) J. exp. Med., 133, 1026 (Thymus-marrow immunocompetence. V. Hydrocortisone-resistant cells and processes in the hemolytic antibody response of mice)

Doenhoff, M. J., Davies, A. J. S., Leuchars, E., And Wallis, V. (1970) Proc. roy. Soc. B., 176, 69 (The thymus and circulating lymphocytes of mice)

Folch, H., AND WAKSman, B. H. (1972) J. Immunol., 109, 1046 (In vitro responses of rat lymphocytes following adult thymectomy. I. Rapid decrease and recovery of responses to mitogens and hemiallogeneic cells)

Gery, I., AND Waksman, B. H. (1972) J. exp. Med., 136, 143 (Potentiation of the T-lymphocyte response to mitogens. II. The cellular source of potentiating mediator(s))

Greaves, M. F., RoItT, I. M., AND Rose, M. E. (1968) Nature (Lond.), 220, 293 (Effect of bursectomy and thymectomy on the responses of chicken peripheral blood lymphocytes to phytohemagglutinin)

JANOSSY, G., AND Greaves, M. F. (1972) Clin. exp. Immunol., 10, 525 (Lymphocyte activation. II. Discriminating stimulation of lymphocyte subpopulations by phytomitogens and heterologous antilymphocyte sera)

- Shohat, M., Greaves, M. F., and Dourmashinin, R. R. (1972) Immunology, 24, 211 (Lymphocyte activation. IV. The ultrastructural pattern of the response of mouse $T$ and $B$ cells to mitogenic stimulation in vitro)

Kapusta, M. A., And Mendelson, J. (1969) Arthr. and Rheum., 12, 463 (The inhibition of adjuvant disease in rats by the interferon inducing agent pyran copolymer) 
Pauly, J. L., Sokal, T. E., And Han, T. (1972) Fed. Proc., 31, 790 Abs (astr. no. 3240) (Whole blood technique for in vitro studies of lymphocyte reactivity in man)

Pearson, C. M., Waksman, B. H., AND Sharp, J. T. (1961) J. exp. Med., 113, 485 (Studies of arthritis and other lesions induced in rats by injection of mycobacterial adjuvant. V. Changes affecting the skin and mucous membranes. Comparison of the experimental process with human disease)

- AND Wood, F. D. (1959) Arthr. and Rheum., 2, 440 (Studies of polyarthritis and other lesions induced in rats by injection of mycobacterial adjuvant. I. General clinical and pathologic characteristics and some modifying factors)

Rodey, G. E., AND Good, R. A. (1969) Proc. Soc. exp. Biol. (N.Y.), 131, 457 (Modification of the in vitro response to phytohemagglutinin of mouse spleen cells by amyloidogenic agents)

Scott, M. T. (1972a) Cellular Immunol., 5, 459 (Biological effects of the adjuvant Corynebacterium parvum. I. Inhibition of PHA, mixed lymphocyte and GVH reactivity)

- (1972b) Ibid., 5, 469 (Biological effects of the adjuvant Corynebacterium parvum. II. Evidence for macrophageT-cell interaction)

Singhal, S. K., AND Richter, M. (1968) J. exp. Med., 128, 1099 (Cells involved in the immune response. IV. The response of normal and immune rabbit bone marrow and lymphoid tissue lymphocytes to antigens in vitro)

Stockman, G. D., Gallagher, M. T., Heim, L. R., South, M. A., And Trentin, J. J. (1971) Proc. Soc. exp. Biol. $N . Y ., 136,980$ (Differential stimulation of mouse lymphoid cells by phytohemagglutinin and pokeweed mitogen)

Waksman, B. H., AND Wennersten, C. (1963) Int. Arch. Allerg., 23, 129 (Passive transfer of adjuvant arthritis in rats with living lymphoid cells of sensitized donors) 